\title{
3 Research Square

\section{Knowledge and Attitude Towards Shisha Smoking Among Health College Students at Princess Nourah University.}

\section{Atheer Aldoss}

Saudi Arabia Ministry of Health

\section{REEM BEN JABER}

Saudi Arabia Ministry of Health

NUJUD ALRUSHUD

King Faisal Specialist Hospital and Research Center

\section{Sarah Al-Qahtani}

Saudi Arabia Ministry of Health

\section{Randah M. AlAlweet}

Saudi Arabia Ministry of Health

Abdulhadi Alqahtani ( $\boldsymbol{Q}$ Ph.abdalhadi@gmail.com )

King Fahad Medical City https://orcid.org/0000-0002-6377-7138

Howeida Hassan Abusalih

Princess Noura Bint AbdulRahman University

\section{Research}

Keywords: Shisha, knowledge, attitude, students, Saudi Arabia

Posted Date: March 10th, 2020

DOl: https://doi.org/10.21203/rs.3.rs-16490/v1

License: (c) (i) This work is licensed under a Creative Commons Attribution 4.0 International License. Read Full License 


\section{Abstract}

Background Despite the negative effects of tobacco use, Saudi Arabia is one of the leading causes of death globally. In Saudi Arabia, $17.1 \%$ of both sexes and $3.0 \%$ of females aged 15 or older smoke. One common way to consume tobacco is through a shisha (waterpipe). This study aims to measure the knowledge of the negative health effects and attitudes toward shisha use among health college students at Princess Nourah University (PNU) in Riyadh, Saudi Arabia.

Method A descriptive, cross-sectional study was conducted at PNU's health colleges, with the 525 student participants selected evenly from each college by using cluster sampling into five health colleges(College of Health and Rehabilitation Sciences, Nursing, Dentistry, Medicine and Pharmacy), data was collected by a pretested, structured questionnaire and was coded, entered and analyzed by Statistical Package for the Social Sciences (SPSS) v.20.

Results $15.4 \%$ is the percentage for who had a history of smoked shisha. The percentage of current smokers was $4.19 \%$. There was no association between the knowledge and shisha smoking practice $(\mathrm{P}=$ $.603)$.

Conclusion In conclusion, the percentage of shisha smoking was high, in spite of having a high level of knowledge. Also, the knowledge toward shisha smoking and shisha practice was not associated. In contrast to a study conducted in USA which showed a slight association between the knowledge and smoking practice. (44)

\section{Introduction}

Tobacco use is one of the leading causes of death globally. The estimated number of people who used tobacco in 2015 was 1.1 billion. ${ }^{(1)}$ According to the WHO, over 6 million deaths across the world in 2017 were a result of exposure to tobacco, either because of direct use or second-hand exposure. ${ }^{(2)}$ The rate of tobacco use showed an increase in the Eastern Mediterranean Region. ${ }^{(1)}$ In Saudi Arabia, $17.1 \%$ of both sexes and $3.0 \%$ of females aged 15 or older currently smoke. ${ }^{(3)}$ One popular method of tobacco use in Arab culture that has recently become more popular across the world is shisha, or as they called it in other places, "argila. ${ }^{(4)}$ The estimated number of people who smoke shisha worldwide is 100 million. ${ }^{(5)}$ Shisha can be defined as flavoured tobacco whose smoke is more aromatic compared to other tobacco products' ${ }^{(6,4)}$ Shisha consists of four parts: head, body, water bowl and hose. After a coal on the shisha's head heats up the tobacco, the smoker inhales the smoke from the head after it passes through the water bowl into the smoker's lungs. ${ }^{(7)}$

Many studies have shown that shisha has the same negative health effects of cigarette smoking. Furthermore, one hour of shisha smoking has a similar effect as smoking 100 cigarettes. ${ }^{(8)}$ In addition, various studies have shown that shisha use is one of the most important risk factors associated with 
ailments such as respiratory diseases, oral cancer, lung cancer, stomach cancer, heart diseases, reduced lung function and decreased fertility. ${ }^{(9)}$

The factors that can be associated with shisha smoking include age, sex and income. One factor that may explain the popularity of shisha smoking could be people's tendency to socialize through a shared activity or interest. ${ }^{(10)}$

Shisha smoking has become more popular among college students in many countries. In 2012 in the USA $11.5 \%$ of the student's population in Florida were shisha smokers, while in Pakistan (2008), $22 \%$ of female college students were smokers. ${ }^{(11,8)}$ Moreover, some studies have shown that in Arab countries there is a high prevalence of shisha smoking among college students. At the national level of Saudi Arabia in Dammam 'on the Arabian Gulf is the capital city of Saudi Arabia's eastern province, a study conducted showed that $3.7 \%$ of the female students were shisha smokers. ${ }^{(12)} 2 \%$ of female students were shisha smokers in a study carried out at King Saud University in Riyadh. ${ }^{(13)}$

The Ministry of Health in Saudi Arabia predicts an increase of shisha smoking among females in the future, which would be a serious issue because tobacco use is associated with many diseases. $(9,14)$ Measuring the knowledge and attitude towards shisha smoking will help to find out what insufficient information students have and what their attitudes are towards shisha smoking. Determining the number of shisha smokers and analysing the factors behind smoking will help to explain why the students are shisha smokers, That will help to build a stronger strategy to avoid the increase of shisha smoking by establishing public health campaigns.

This study aims to measure the knowledge of and attitude towards shisha use among health college students at Princess Nourah University in Riyadh, Saudi Arabia.

\section{Methodology}

A descriptive, cross-sectional and facility-based study was conducted at Princess Nourah University (PNU), Riyadh, Saudi Arabia which is a female university. The target population was all students in PNU's health colleges (Health and Rehabilitation Sciences, Nursing, Dentistry, Medicine and Pharmacy) except the foundation programme. The calculated sample was 576 participants who were selected evenly from the five colleges by using cluster sampling; the number of students from each college was 115, while the response rate was $91.1 \%$ (525 students out of 576). Students available at the time of data collection were chosen from all academic levels. Data was collected by using self-administrated, structured questionnaires. The questionnaires included 31 questions, classified into four parts. The first part included demographic factors (college, age and marital status). The second part contained 8 questions to measure the knowledge of the negative health effects toward shisha smoking. The third part contained 5 questions to measure the attitude towards shisha smoking and 6 questions to gather students' opinions toward shisha smoking. The last part contained 9 questions, only for current smokers, included questions to find out why, where and with whom they are smoking shisha and if they have the intention to quit 
smoking. Before the data collection, a pilot study of 6 students was conducted to test the validity of the questionnaire.

Data was coded and entered into the Statistical Package for Social Sciences (SPSS). Descriptive statistics were in the form of frequency tables to describe the socio-demographic factors and the percentage of shisha smoking among the students, students' friends and family members. A chi-square test was used to determine the relationship between dependent and independent categorical variables, with a cutoff point of less than 0.05 . The test was used to find out the relationships between sociodemographic factors and the knowledge, attitudes and shisha smoking habits of participants. It was also used to find out differences in knowledge, attitudes and opinions toward shisha smoking among the smokers and non-smokers.

\section{Ethical approval}

IRB approval was given before the start of the study. Informed consent was taken from all participants. The information and data collected were kept confidential. This study included no personal information or identifiers such as names or ID information. There were no risks for the participants, as the research was verbal with no actions or experiments. Two parties benefitted: the participant and society.

\section{Results}

The results are divided into four sections: First, the socio-demographic factors for the sample population. Second, the prevalence of shisha smoking among health college students. Third, percentages of the students' knowledge, attitude and perceptions. Fourth, the relationship of age with knowledge and attitude.

\section{Socio-demographic factors}

Table (1) shows the percentages of the different age groups; $98.5 \%$ of the students were between 19 and 25 . The percentage of the students who were married or have been married was $3.6 \%$, while the rest of the students were single. 
Table 1

Frequency of socio-demographic factors among health colleges students in PNU.

\begin{tabular}{|lll|}
\hline Age & Frequency & Percent \\
\hline less than or equal 18 years & 4 & 0.8 \\
Between 19-25 years & 517 & 98.5 \\
More than 25 years & 4 & 0.8 \\
Total & 525 & 100 \\
\hline Marital statues & & \\
Single & & \\
Ever marriage & 504 & 96.4 \\
Total & 14 & 3.6 \\
\hline
\end{tabular}

\section{Prevalence of shisha smoking among health college students at PNU}

Table (2) shows the percentage of the students who had ever smoked shisha. The total percentage was $15.4 \%$ (80 out of 525 ). $27.5 \%$ of the smokers were current smokers and $11.3 \%$ were ex-shisha smokers, while $61.3 \%$ of them had smoked only one time.

Table 2

Percentages of shisha smoking among health colleges

\begin{tabular}{|lll|}
\hline Prevalence of shisha smoking & Frequency & Percent \\
\hline No & 444 & 84.6 \\
Yes & 81 & 15.4 \\
Total & 525 & 100 \\
\hline Shisha smoking status & & \\
& & \\
Once just to try & 49 & 61.3 \\
For period of time but I quit & 9 & 11.3 \\
Yes, I still smoking & 22 & 27.5 \\
Total & 80 & 100 \\
\hline
\end{tabular}

\section{Knowledge, attitude and perception toward shisha smoking}

Figure (1) presents the level of knowledge of shisha smoking the students have. Approximately $59.4 \%$ of the students had good knowledge, $36 \%$ of the students had fair knowledge and few of the students had poor knowledge - only $4.6 \%$.

Figure (2) presents the attitudes the students have toward shisha smoking. Most of the students (72.6\%) have a neutral attitude toward shisha smoking, and only $5.1 \%$ of the students have a positive attitude. 
Table (3) shows there is association between age and knowledge toward shisha smoking: $(P=.033)$ of the students aged $19-25$ years.

Table 3

Association between knowledge and age among health colleges students in

PNU

\begin{tabular}{|llllll|}
\hline \multirow{2}{*}{ Age } & \multicolumn{2}{l}{ Knowledge } & & P Value \\
\cline { 2 - 5 } & Poor & fair & good & Total & .033 \\
less than or equal 18 years & 1 & 3 & 0 & 4 & \\
Between 19-25 years & $25 \%$ & $75 \%$ & $0.0 \%$ & $100 \%$ & \\
More than 25 years & 23 & 186 & 308 & 517 & \\
Total & $4.4 \%$ & $36 \%$ & $59.6 \%$ & $100 \%$ & \\
& 0 & 0 & 4 & 4 & \\
& $0.0 \%$ & $0.0 \%$ & $100 \%$ & $100 \%$ & \\
& 24 & 189 & 312 & 525 & \\
& $4.6 \%$ & $35.2 \%$ & $64.8 \%$ & $100 \%$ & \\
\hline
\end{tabular}

Table (4) shows $72.7 \%$ of the students aged $19-25$ years had a neutral attitude and only $5 \%$ of them had a positive attitude. Of the students who were more than 25 years old, $75 \%$ of had a neutral attitude. However, $72 \%$ of the single students had a neutral attitude and only $5.4 \%$ of them had a positive attitude. The results show no difference between the attitude and socio-demographic factors.

Table 4

Association between attitude and age among health colleges students in PNU.

\begin{tabular}{|llllll|}
\hline Students colleges & \multicolumn{2}{l}{ Attitude toward shisha } & & Total & $\begin{array}{l}\text { P- } \\
\text { Value }\end{array}$ \\
\cline { 2 - 4 } & $\begin{array}{l}\text { Negative } \\
\text { attitude }\end{array}$ & $\begin{array}{l}\text { Neutral } \\
\text { attitude }\end{array}$ & $\begin{array}{l}\text { Positive } \\
\text { attitude }\end{array}$ & & \\
\hline less than or equal & 2 & 2 & 0 & 4 & .21 \\
18 years & $50.0 \%$ & $50.0 \%$ & $0.0 \%$ & $100.0 \%$ & \\
Between 19-25 years & 115 & 376 & 26 & 517 & \\
More than 25 years & $22.2 \%$ & $72.7 \%$ & $5.0 \%$ & $100.0 \%$ & \\
Total & 0 & 3 & 1 & 4 & $100.0 \%$ \\
& $0.0 \%$ & $75.0 \%$ & $25.0 \%$ & 525 & \\
& 117 & 381 & 27 & $100.0 \%$ & \\
\hline
\end{tabular}

\section{Discussion}

In this study, the percentage of shisha smoking among the students is $15.4 \%$ (27.5\% of them are current smokers, $61.3 \%$ smoked once and $11.3 \%$ are ex-smokers), which is slightly less than in a study conducted at King Saud University in Riyadh that showed $18.9 \%$ of the students smoked shisha at least once during 
their lifetime ${ }^{(15)}$ However, another study conducted earlier at King Saud University, in 2007, showed a lower prevalence $(2 \%)$ in comparison to the results in this study. ${ }^{(13)}$

There is no different level of knowledge between health colleges. The majority of the participants in all colleges have a good level of knowledge, with knowledge increasing with age. The high level of knowledge could be a reflection of the students' backgrounds. This is in contrast to a study that was conducted in Pakistan that found the level of knowledge is different from college to college, specifically that pharmacy students have better knowledge than medical students. ${ }^{(16)}$

The study finds no association between the knowledge of shisha smoking and smoking practice. This is in contrast to several studies conducted around the world: In the USA a slightly significant association between knowledge and smoking practice was shown. ${ }^{(17)}$ This is in addition to another study done in Turkey in 2015 which showed that smokers have less knowledge compared to non-smokers. ${ }^{(18)}$ A study conducted in London also found out that shisha smokers have less knowledge compared to non-

smokers. ${ }^{(19)}$ In this study, the students have a similar level of knowledge, which could explain why there is no association between the knowledge and shisha smoking practices.

The results show that most shisha smokers have a family member who also smokes shisha. Likewise, a study in Dammam showed that students are more likely to be a smoker if their mother or father is a smoker. ${ }^{(12)}$ The association between being a smoker and having a family member who smokes could be because of the availability of the shisha in their home. This is in contrast to a study conducted in Pakistan found out there is no association between shisha smoking and having a smoker in the family. (20) The results also show that most of the students who have a positive attitude have a shisha smoker friend. In the same way, a previous study in Riyadh showed that most of the students who have a positive attitude toward shisha smoking reported that one of their closest friends used shisha. ${ }^{(15)}$

\section{Limitations}

This study had one limitation The study targeted students in health colleges, so the results cannot be generalized to non-health colleges.

\section{Conclusion}

In conclusion, the percentage of shisha smoking was high, in spite of participants having a high level of knowledge. There was no association between colleges and knowledge of shisha smoking. Most of the students who are shisha smokers or have tried during their lifetimes have a shisha smoker in their family.

\section{Declarations}

\section{Ethics approval and consent to participate:}


The ethics approval was obtained from the Human Research Ethics Committee, Princess Nourah University, Riyadh, Saudi Arabia. The consent of the participants was written.

\section{Consent for publication:}

Not applicable.

\section{Availability of data and material:}

Not applicable.

\section{Funding:}

Not applicable

\section{Acknowledgment:}

We would like to thank the Saudi Association for Scientific Research (SASR) for providing their intellectual, technical and logistical support throughout the duration of the project..

\section{Competing interests:}

The authors declare that they have no competing interests

\section{References}

1. World health organization (WHO). Prevalence of tobacco smoking [Internet]. World health organization. 2015 [cited 20 Sep 2016]. Available from: http://www.who.int/gho/tobacco/use/en/

2. World health organization (WHO). Tobacco [Internet]. World health organization . 2016 [cited 20 Sep 2016]. Available from: http://www.who.int/mediacentre/factsheets/fs339/en/

3. World health organization (WHO). Report on the Global Tobacco Epidemic [Internet]. World health organization. 2015 [cited 1 Mar 2017]. Available from: http://www.who.int/tobacco/surveillance/policy/country_profile/sau.pdf

4. Maziak W, Ward D, AfifiSoweid A, Eissenberg T. Tobacco smoking using a Water pipe : a re-emerging strain in a global epidemic. PubMed . 2004[5 Sep 2016] ; 13(4):327-33. Available from: https://www.ncbi.nlm.nih.gov/pubmed/15564614

5. The Sacred Narghile. 2006. (updated 2008) [ 2 Sep 2016]; 5:17. Available from : http://www.sacrednarghile.com/en/index.Php

6. Primack BA, Sidani J, Agarwal AA, Shadel WG, Donny EC, Eissenberg TE. Prevalence of and associations with waterpipe tobacco smoking among U.S. university students. Ann Behav Med. Aug; 2008 36(1):81-86. Available from: https://www.ncbi.nlm.nih.gov/pubmed/18719977 
7. Holtzman A, Babinski D, Merlo L. Knowledge and Attitudes Toward Hookah Usage Among University Students. Journal of American College Health. 2013 [15 Sep 2016] ;61(6):362-370. Available from: http://www.tandfonline.com/doi/full/10.1080/07448481.2013.818000?scroll=top\&needAccess=true

8. Masood Z, Sohil K, Rauf A, Majeed M, Ashraf K, Abbas S. Perceptions of Shisha Smoking Among University Students in Pakistan. Journal of university medical and dental college [internet]. 2013 [cited 8 Sep 2016]; 4: 9-15. Available from: https://jumdc.tuf.edu.pk/articles/volume-4/no-2/9-15.pdf.

9. CDC - Fact Sheet - Hookahs - Smoking \& Tobacco Use [Internet]. Smoking and Tobacco Use. 2016 [20 Sep 2016]. Available from: https://www.cdc.gov/tobacco/data_statistics/fact_sheets/tobacco_industry/hookahs/

10. AL-Naggar, R. A., Saghir, F. S. Water Pipe (Shisha) Smoking and Associated Factors Among Malaysian University Students. Asian Pacific journal of cancer prevention[internet]. 2011 January [12Feb 2017]; 12: 3041-3047. Available at : https://www.researchgate.net/publication/221680936

11. Rahman S, Chang L, Hadgu S, Salinas-Miranda A, Corvin J. Prevalence, Knowledge, and Practices of Hookah Smoking Among University Students, Florida, 2012. 2014;11. Available from: https://www.cdc.gov/pcd/issues/2014/14_0099.htm

12. Koura, M., Bahnassy, A. and Al-Dossary, A. Smoking pattern among female college students in Dammam, Saudi Arabia. Journal of Family and Community Medicine[online]. 2011[7 Dec 2016]; 18(2), p.63. Available from: http://dx.doi.org/10.4103/2230-8229.83370

13. Subban M, AlKblaiwi T, Gbandourab Smoking among health science university students in Riyadh, Saudi Arabia . Saudi Med J. 2009[ 7 Dec 2016]; 30(12): 1611. Available from: https://www.smj.org.sa/index.php/smj/article/download/6812/4586

14. Team M. Kingdom of Saudi Arabia - Ministry of Health Portal [Internet]. 2017 [cited 11 Sep 2017]; Available from: http://www.moh.gov.sa/en/Ministry/Statistics/Pages/healthinformatics.aspx

15. Allohidan F, Alanazi A, Azzahrani M, Alrashoud M. Knowledge, Practice and Attitudes Regarding Hookah (Water Pipe) Smoking among College Students Studying Health Sciences in Riyadh, Saudi Arabia. International Journal of Academic Scientific Research.2017;5(1):54-65. Avalible from: http://www.ijasrjournal.org/wp-content/uploads/2017/03/MS19X-17.pdf

16. Kumar A, Baig S, Ansari S, Rizvi N, Sharif H, Beg A, et al.. Comparison of Shisha Smoking Behavior among Medical and Pharmacy Students. Journal of Behavioral and Brain Science[internet]. 2016[4 Feb 2017];6:269-279. Available from: http://file.scirp.org/pdf/JBBS_2016070514425054.pdf

17. Nuzzo E, et al., Associations between hookah tobacco smoking knowledge and hookah smoking behavior among US college students. Oxford Journal[internet]. 2012 Sep; 28(1): 92-100. Available ftom PupMed : https://academic.oup.com/her/article/28/1/92/595520/Associations-betweenhookah-tobacco-smoking

18. Sahin S, Cinar N. Perceptions of Turkish University Students about the Effects of Water Pipe Smoking on Health. Asian Pacific Journal of Cancer Prevention[internet]. 2015 [cited ]; 16:[46154621]. Available from: http://journal.waocp.org/article_31134_f398af1ec6f6d3d73692bc7518fa39a9.pdf 
19. Noonan D, Patrick M. Factors Associated With Perceptions of Hookah Addictive and Harmfulness Among Young Adults. Substance Abuse.[internet].2013;34(0889): [83-85]. Available from: http://www.tandfonline.com/doi/full/10.1080/08897077.2012.718251.

20. Anjum Q, Ahmed F, Ashfaq T. Knowledge, attitude and perception of water pipe smoking (Shisha) among adolescents aged 14-19 years[internet]. 2008; 58(6) Available from: http://www.jpma.org.pk/PdfDownload/1419.pdf

\section{Figures}

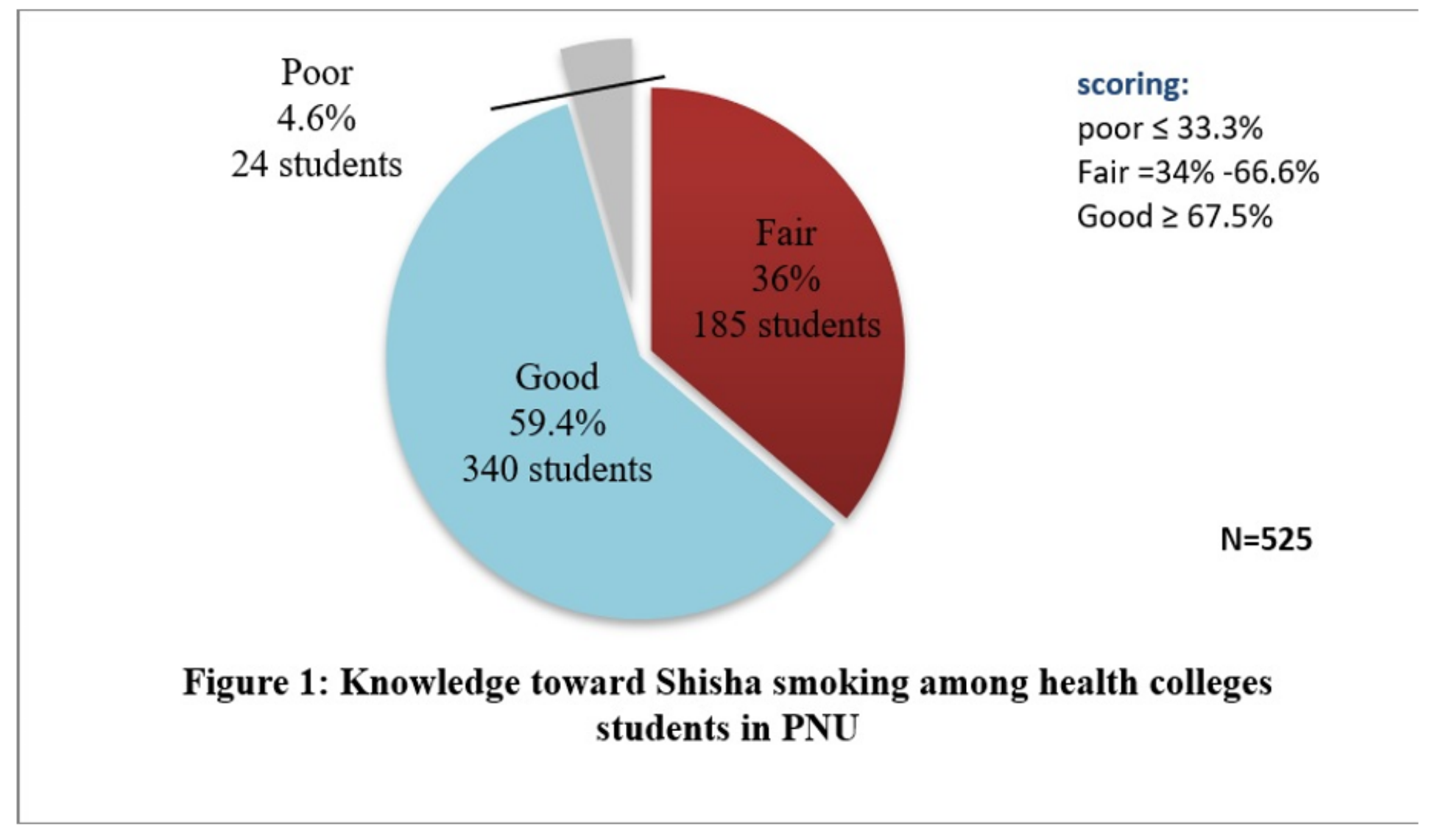

\section{Figure 1}




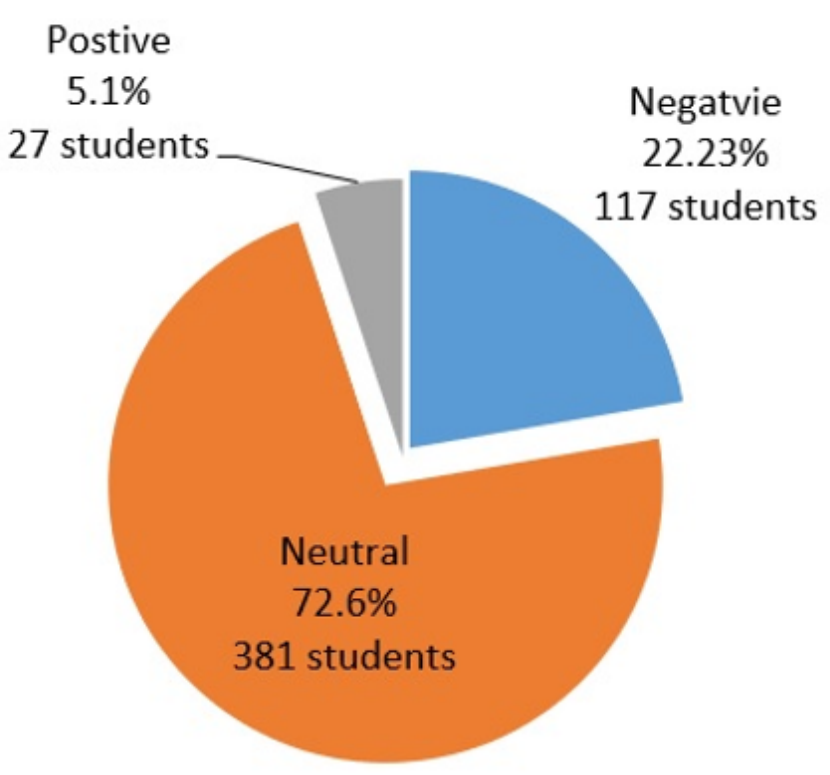

$\mathrm{N}=525$

Figure 2: Attitdue toward Shisha smoking among stdunets in health colleges

Figure 2 